\title{
Sequential optimizations of Aspergillus awamori EM66 exochitinase and its application as biopesticide
}

\author{
Ghada E. A. Awad ${ }^{1}$, Walaa A. Abdel Wahab ${ }^{1}$, Mona Hussein ${ }^{2}$, Ahmed El-diwany ${ }^{1}$, Mona A. Esawy ${ }^{1 *}$ \\ ${ }^{1}$ Department of Chemistry of Microbial and Natural Products, National Research Centre, Tahrir Street, Dokki Cairo, Egypt. \\ ${ }^{2}$ Department of Pests and Plant Protection, Centre of Excellence for Advanced Sciences, National Research Centre, Tahrir Street, Dokki Cairo, Egypt.
}

\begin{tabular}{|c|c|}
\hline ARTICLE INFO & ABSTRACT \\
\hline Article history: & \multirow{5}{*}{$\begin{array}{l}\text { Sequential optimization strategy was achieved based on statistical experimental designs for enhancement of } \\
\text { Aspergillus awamori EM66 exochitinase production. Firstly, 2-level Plackett-Burman design was accomplished } \\
\text { for distinguishing between the bioprocess parameters, which improve the exochitinase production. Second } \\
\text { optimization step was implemented through central composite design (CCD), for optimization variables } \\
\text { amounts which have the highest positive effect on exochitinase production. Maximum activity (5998mU/ml) for } \\
\text { exochitinase reported approximately } 22 \text { fold increase compared to the basal medium activity. Mortality } 92 \% \text {, } \\
86.67 \% \text { and } 65.67 \% \text { was recorded when the partial pure fungal exochitinase was applied to the diet of the } \\
\text { greater wax moth larvae, Galleria mellonella, the cotton leaf worm, Spodoptera littoralis, and the black } \\
\text { cutworm, Agrotis ipsilon, respectively. The results indicated to the importance of Aspergillus awamori EM66 } \\
\text { exochitinase as an effective bio- pesticide. }\end{array}$} \\
\hline Received on: $27 / 06 / 2016$ & \\
\hline Accepted on: 10/09/2016 & \\
\hline Available online: $27 / 02 / 2017$ & \\
\hline $\begin{array}{l}\text { Key words: } \\
\text { Aspergillus awamori; Bio } \\
\text { pesticides; Central composite } \\
\text { design; Exochitinase. }\end{array}$ & \\
\hline
\end{tabular}

\section{INTRODUCTION}

Hard environments are permanently predictable to accord unrivalled microorganisms have new feature. Honey osmophilic property commended it to be good medium for dominant spores worthy to produce bio-products with unique properties (Esawy et al., 2011; Esawy et al., 2012; Esawy et al., 2013). Chitin, is a $\beta$-1,4-linkedNacetylglucosaminehomopolymer. It is consider the second most copious polysaccharide in nature. Chitin is considered as one of the main component of exoskeletons of some insect, fungus cell walls and crustacean shells (Gooday, 1990; Crosby and Alfred, 2004). It is also exists in several body ingredients of invertebrates and as a bacterial product (Tanaka et al., 1999; Nawani and Kapadnis, 2005). Chitinases (E.C.3.2.1.14) is enzymes have the ability to hydrolyze in soluble chitin to its oligo and monomeric components. Chitinases could be divided into two main enzymes, exochitinases and endochitinases (Graham and Sticklen,

\footnotetext{
* Corresponding Author

E-mail: mona_esawy@hotmail.com
}

1994). Endochitinases (EC 3.2.1.14) can split chitin at random internal sites yielded a soluble, low-molecular mass multimers of $\mathrm{N}$-Acetylglucosamine (GlcNAc) like chitotetrose, chitotriose, and diacetylchitobiose. Exochitinase consisted of two subcategories: $\beta$ 1, $4 \mathrm{~N}$-acetyl glucosaminidases and exochitinases (EC 3.2.1.29), the aim of this work which can stimulate the release of diacetylchitobiose starting at the non-reducing end of chitin chains (Chuan, 2006). Many researchers pay attention to chitinases because of their wide range of biotechnological applications, especially in chitooligosaccharides production, glucosamines, and GlcNAc have an massive pharmaceutical potential (Singh et al., 2009) and, Chitinases can be also used as bio-control agents against fungal phytopathogens in agriculture field due to their ability to hydrolyze the chitinous fungal cell wall (Maisuria et al., 2008). Crop pests control by the use of chitinase holds a great promise as an alternative to the use of chemicals (Kramer, 1997). Several years ago, statistical design experimental techniques have been employed for reaching to the most favorable conditions. It was achieved by evaluating the parameters effects and conquer the abuse of factor interactions (Ren et al., 2006, Liu et al., 2013). 
Response surface method (RSM) is one of the popular techniques that are used widely in the biotechnology industry (Wejse et al., 2003, Rui et al., 2009). RSM is a combination of mathematic and statistical techniques for experiments design, building models, estimating factors effects, and looking for the optimum conditions. RSM is a convenient road for developing optimum processes with precise conditions that has also minimized production cost of many processes by efficient screening process parameters. The optimal conditions or the region that fits the operation specification can be determined by the RSM via a curvature approach (Elibol and Dursun, 2002).

Egyptian cotton leaf worm, Spodoptera littoralis (Lepidoptera: Noctuidae), an important pest that led to vast loss in vegetables varieties, fodder, and fiber crops (Güz et al., 2013). It is damages wide types of crops, such as cotton, tobacco, and corn in countries located around the Mediterranean Basin and in Southeast Asia (Balachowsky, 1972, Sneh et al., 1981). Number of moth species offensive honey bees, honey polen and wax. Galleria mellonella, causes serious losses to commercial beekeepers every year. Black cutworm causes an economic threat to many agricultural crops. In Pennsylvania field crops, it is most often a pest of corn. It is also cause trouble in wheat and tobacco (Robinson et al., 2001).

The present report is an attempt to improve exochitinase production by honey isolates Aspergillus awamori EM66 through optimization of medium components. The enzyme was partially purified by $30 \%$ acetone. Finally, the study focused in the insecticidal activity against three serious insects which destroy valuable and economic crops, the greater wax moth larvae, Galleria mellonella, the Egyptian cotton leaf worm, Spodoptera littoralis and the black cutworms, Agrotis ipsilon.

\section{MATERIALS AND METHODS}

\section{Microorganisms and maintenance}

The fungal used throughout this work, was previously identified as Aspergillus awamori EM66 (Kansoh et al., 2015) based on morphological characterization and 18S rRNA sequence analysis. A. awamoriEM66 was routinely grown on Potato dextrose agar (PDA) medium at $30^{\circ} \mathrm{C}$ and preserved at $-80^{\circ} \mathrm{C}$ in $50 \%(\mathrm{v} / \mathrm{v})$ glycerol.

\section{Exochitinase assay}

Exochitinase activity was determined according to the method of (Matsumoto et al., 2004) using the chromogenic substrate $\mathrm{p}$ - nitro phenyl- $\beta$-D-N-acetylglucoseaminide (PNP- $\beta$ GlcNAc) as a substrate. One unit of the enzyme activity was acquainting as the enzyme amount releasing $1 \mu \mathrm{mol}$ of $\mathrm{P}$ nitrophenol per minute under the specified assay conditions.

\section{Enzyme production conditions}

Initially, the basal medium (BM) for exochitinase production contained ( $\mathrm{g} \%$ ): (Chitin,0.5; peptone, 0.5; yeast extract, $0.3 ; \mathrm{NaNO}_{3}, 0.2 ; \mathrm{K}_{2} \mathrm{HPO}_{4}, 0.1 ; \mathrm{KCl}, 0.05 ; \mathrm{MgSO}_{4} .7 \mathrm{H}_{2} \mathrm{O}$,
$0.001 \mathrm{pH}$ was adjusted to 6.0.Conical flasks $(250 \mathrm{ml})$ had $50 \mathrm{ml}$ of (BM) were inoculated with one $\mathrm{ml}$ of spore suspension include approximately $\left(1 \times 10^{6} \mathrm{CFU} / \mathrm{ml}\right)$.

Inoculated flasks were incubated at $30{ }^{\circ} \mathrm{C}$ for 6 days in a rotary shaker adjusted at $200 \mathrm{rpm}$. At the end of incubation period cultures were centrifuged for $15 \mathrm{~min}$ using the cooling centrifuge. Culture supernatant was used as the crude enzyme. Results reported are the average values with standard deviations.

\section{Experimental designs \\ Plackett-Burman design}

For multivariable processes such as biochemical systems, in which numerous potentially influential factors were involved, it is needful to analyze the process with an initial screening design prior to optimization (Box et al., 1978). Plackett-Burman experimental design (Plackett and Burman,1946) was used to evaluate the relative importance of various nutrients for exochitinase production by A. Awamori EM66 in submerged fermentation.

Fifteen components were selected for the study, each variable represented at two levels, high value $(+1)$ and low value $(-1)$ in 16 trials as shown in (Table 1 ).

Incubation time, $\mathrm{pH}$, glucose, insect, soya bean, chitin, wheat flour, $\mathrm{NaNo}_{3}, \mathrm{CuSO}_{4}, \mathrm{MgSO}_{4}, \mathrm{~K}_{2} \mathrm{HPO}_{4}, \mathrm{ZnSO}_{4}, \mathrm{FeSO}_{4}$, $\mathrm{MnSO}_{4}, \mathrm{CaCl}_{2}$, each row represented a trial run and each column represented an independent variable concentrations. PlackettBurman experimental design was based on the first order linear model:

$$
\mathrm{Y}=B_{0}+\Sigma B_{i} X_{i} \text { Eq. } \quad 1
$$

Where, $Y$ was the response (exochitinase production), $B_{0}$ was the model intercept and $B_{i}$ was the variables estimates. The effect of each variable was estimated by following equation,

$$
E\left(X_{i}\right)=2\left(\Sigma M_{i}{ }^{+}-M_{i}{ }^{-}\right) / N \quad \text { Eq. } 2
$$

Where, $E\left(X_{i}\right)$ was the effect of the tested variable. $M_{i}^{+}$and $M_{i}^{-}$ represented exochitinase production from the trials where the variable $\left(X_{i}\right)$ measured was present at high and low concentrations, respectively and $N$ was the number of trials in Eq. 2. The standard error (SE) of the concentration effect was the square root of the variance of an effect, and the significance level ( $p$ value) of each concentration effect was determined using student's $t$-test

$$
t\left(X_{\mathrm{i}}\right)=E\left(X_{i}\right) / \mathrm{SE} \quad \text { Eq. } 3
$$

Where, $E\left(X_{i}\right)$ was the effect of variable $X_{i}$. 
Table1.Coded levels and real values for Plackett-Berman experiment

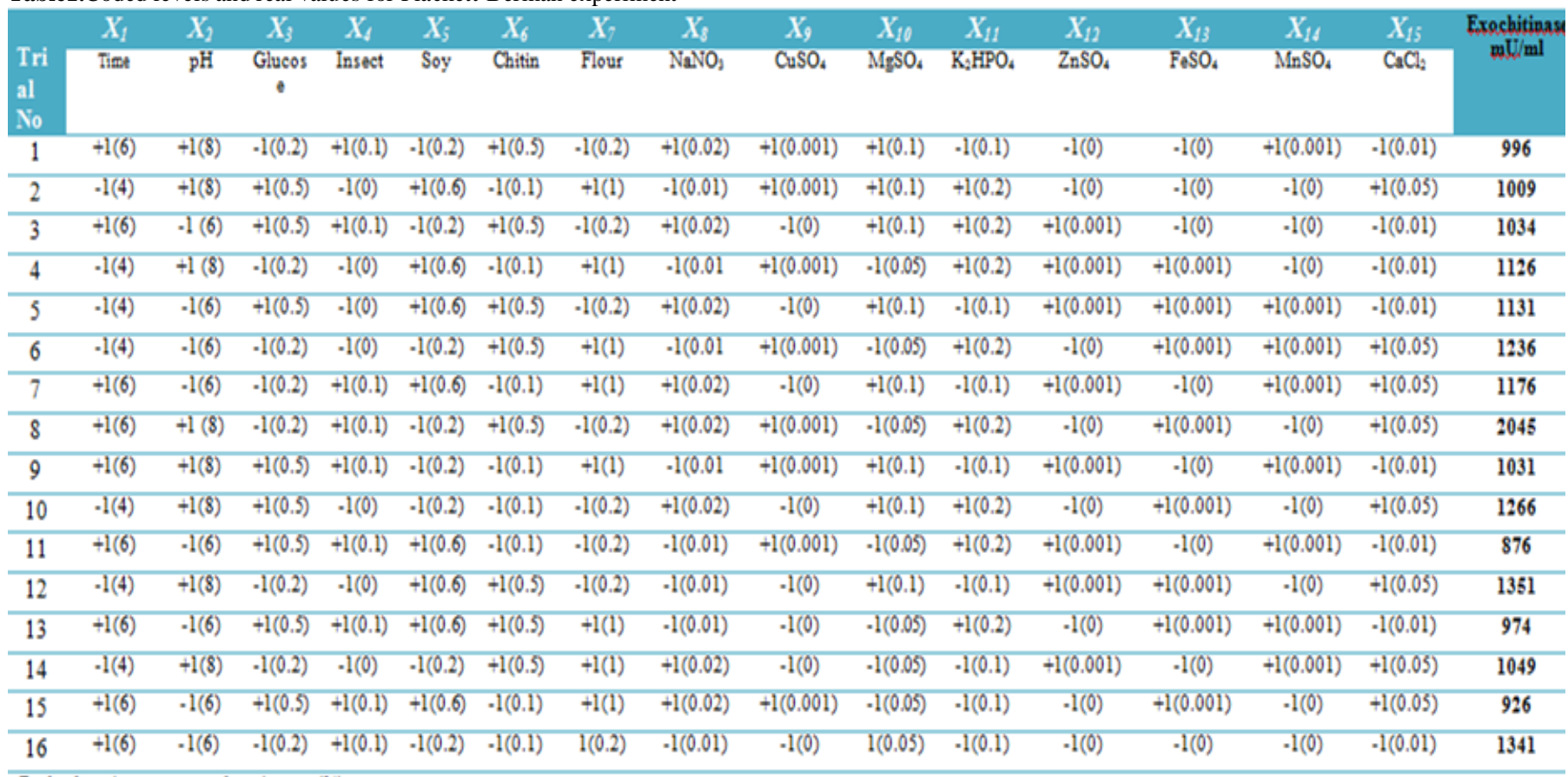

Real values (given in parentheses) are in (\%)

\section{Central composite design}

After the components identification which affecting the production by Plackett-Burman design three variables (Chitin, $\mathrm{MnSO}_{4}$, and $\mathrm{CaCl}_{2}$ concentrations) for exochitinase were chosen for response surface methodology of central composite design (CCD). CCD proposed by (Adinarayana et al., 2003; Awad et al., 2013) was selected for this study. A $2^{3}$ factorial design with six star points and six replicates at the central points were used to fit the second-order polynomial model. The experimental design consisted of 20 runs and the independent variables were studied at five different levels. The experimental design used for the study was represented in Table 3. All the experiments were done in triplicate and the average of exochitinase production obtained was taken as the dependent variable or response $(Y)$. The second-order polynomial coefficients were calculated and analyzed using the 'SPSS' software (Version 16.0). Second degree polynomials, Eq.(4), which includes all interaction terms, were used to calculate the predicted response:

$Y$ activity $=\beta_{0}+\beta_{1} X_{1}+\beta_{2} X_{2}+\beta_{3} X_{3}+\beta_{11} X_{1}{ }^{2}+\beta_{22} X_{2}^{2}+\beta$ ${ }_{33} C_{3}^{2}+\beta_{12} X_{1} X_{2}+\beta_{13} X_{1} X_{3}+\beta_{23} X_{2} X_{3}$ Eq. (4)

Where, $\mathrm{Y}$ activity was the predicted production of exochitinase $(\mathrm{mU} / \mathrm{ml}), \mathrm{X} 1, \mathrm{X} 2$ and $\mathrm{X} 3$ were the independent variables corresponding to the concentration of Chitin, $\mathrm{MnSO}_{4}$, and $\mathrm{CaCl}_{2}$ respectively. $B_{0}$ was the intercept, $B_{1}, B_{2}, B_{3}$ were linear coefficients, $\beta_{11}, \beta_{22}, \beta_{33}$ were quadratic coefficients, $\beta_{12}, \beta_{13}, \beta_{23}$ were cross product coefficients. Statistical analysis of the model was performed to evaluate the variance analysis (ANOVA).
Statistical significance of the model equation was determined by Fisher's test value, and the proportion of variance explained by the model was given by the multiple coefficient of determination for each variable. The quadratic models were represented as contour plots (3D) and response surface curves were generated by using STATISTICA (0.6).

\section{Partial purification}

The optimized culture supernatant (crude exochitinase) of Asperigillus awamori EM66 produced on the previous medium was fractionated using ethanol concentrations (30-80\%). The precipitate was obtained by centrifugation $(10000 \mathrm{xg}, 15 \mathrm{~min}$. at $4^{\circ} \mathrm{C}$ ) and suspended in an appropriate volume of $0.05 \mathrm{M}$ acetate buffer ( $\mathrm{pH}$ 5.0). The enzyme activity was determined for each fraction as described before. Also, protein content was evaluated for each fraction as described by Lowry et al., (1951).

\section{Insect bioassay Insects}

Fourth instars larvae of three lepiopteran insect pests were used to test the exochitinase efficiency. These tested insects were the great wax moth larvae, Galleria mellonella, the Egyptian cotton leaf worm, Spodoptera littoralis and the black cutworms, Agrotis ipsilon. Greater wax moth culture G. Mellonella was preserve, on a modified artificial diet according to (Metwally et al., 2012). Cultures of the black cut worm, A. ipsilon (Huf.) and the cotton leaf worm, S. littoralis (Boisd.) larvae were reared on castor leaves Ricinus communis L. according to (Hussein, 2004). 


\section{Bioassay}

Exochitinase application occurred through mixing with insect media. Two $\mathrm{ml}$ of the partial pure enzyme suspension was mixed with $50 \mathrm{~g}$ of the artificial diet for the greater wax moth in a 150 CC cups (Metwally et al., 2012). For the other two pests, the leaves of castor were sprayed with $2 \mathrm{ml}$ enzyme suspension and left to dry in a $9 \mathrm{~cm}$ Petri dish lined with no. 1 Whatman-filter paper. Five insect were added for each cup and Petri dish and 15 replicates for each tested insect. The treatments were kept in $25 \pm$ $1^{\circ} \mathrm{C}$ and larval mortalities were recorded after $48 \mathrm{~h}$.

\section{RESULTS AND DISCUSSION}

At the preliminary stage of our study, the honey isolate A. awamori EM66 was tested for exochitinase production. The result indicated that it was exochitinase producer with activity equal $(270 \mathrm{mU} / \mathrm{ml})$ and $176.36 \mathrm{mg}$ protein. Consequently, the specific activity was evaluated to be $1.531 \mathrm{U} / \mathrm{mg}$ by using the basal medium under submerged fermentation condition. Production of chitinase by Aspergillus spp. was studied in many reports as a potential producer for both endochitinase and exochitinase (Vionis et al., 1996, Xia et al., 2001, Nawani et al., 2002, Rattanakit et al., 2007, Brzezinska and Jankiewicz, 2012).

\section{Exochitinase production optimization by multi-factorial experiments}

In this work a sequential optimization approaches were used. The first trail aimed to screen the nutritional factors influencing growth of A. awamori EM66 with respect to exochitinase production. The second step aimed to optimize the influencing factors which controlling enzyme production process.

\section{Estimation of the factors affecting exochitinase productivity}

Firstly, the Plackett-Burman design was done to explain the relations between different medium components. Fifteen factors $\left(\mathrm{X}_{1}-\mathrm{X}_{15}\right)$ included culture conditions and medium components were selected for optimization process. Exochitinase average activity for the different attempts were formulated as $\mathrm{mU}$ $/ \mathrm{ml}$ and represented in Table 1 . Main effect was estimated as the difference between both the averages of measurements made at the high level $(+1)$ and at the low level $(-1)$ of that factor. Table 1 showed a wide divergence from 876 to $2045 \mathrm{mU} / \mathrm{ml}$ on exochitinase activity. Factors effects on the enzyme activity were estimated and showed graphically in Fig. 1. It was introduced the view for factor ranking estimated by Plackett-Burman design. This variation reflected medium optimization significant to reach high productivity. Data analysis from Plackett-Burman tested contained a first order (main effects) model. Regression coefficients analysis for examined variables for the exochitinase were :incubation time, $\mathrm{pH}$, glucose, dried insects, soya bean, chitin, wheat flour, $\mathrm{NaNO}_{3}, \mathrm{CuSO}_{4}, \mathrm{MgSO}_{4}, \mathrm{~K}_{2} \mathrm{HPO}_{4}, \mathrm{ZnSO}_{4}$, $\mathrm{FeSO}_{4}, \mathrm{MnSO}_{4}, \mathrm{CaCl}_{2}$. Chitin, $\mathrm{MnSO}_{4}, \mathrm{CaCl}_{2}, \mathrm{FeSO}_{4}, \mathrm{NaNO}_{3}$, $\mathrm{K}_{2} \mathrm{HPO}_{4}, \mathrm{CuSO}_{4}$ and incubation period showed positive effect on exochitinase activity. Wheat flour, soya bean, glucose, $\mathrm{pH}$,
$\mathrm{MgSO}_{4}, \mathrm{ZnSO}_{4}$ and dried insect, were contributed negatively. First order model explained the link between the fifteen factors and the exochitinase activity which presented as follows:

Yactivity $=853.0953+4.532 X_{1}+38.26265 X_{2}-987.144 X_{3}+4152.63 X$ $4-528.983 \mathrm{X}_{5}-9.469752 \mathrm{X}_{6}$

$-373.737 X_{7}-1768.74 X_{8}+26445.02 X_{9}-529.596 X_{10}+2311.588 X_{11}+$ 193353.7X $X_{12}+181015.2 X_{13}-10997.6 X_{14}+4499.06 X_{15}$ Eq.(5)

Table 2 revealed the t-test, $\mathrm{p}$ effect and confidence level. The variables reported confidence level above $98 \%$ in the Plackett-Burman design which were selected for further optimization; they were (Chitin, $\mathrm{MnSO}_{4}$ and $\mathrm{CaCl}_{2}$ ). Many reports showed the importance of chitin as a significant factor affecting chitinase production. It was reported that chitin is an essential factor influencing chitinase production by Streptomyces lividans (Vionis et al., 1996). In similar, colloidal chitin was proved to be the best substrate for production of chitinase in Microbispora sp. (Nawani et al., 2002).

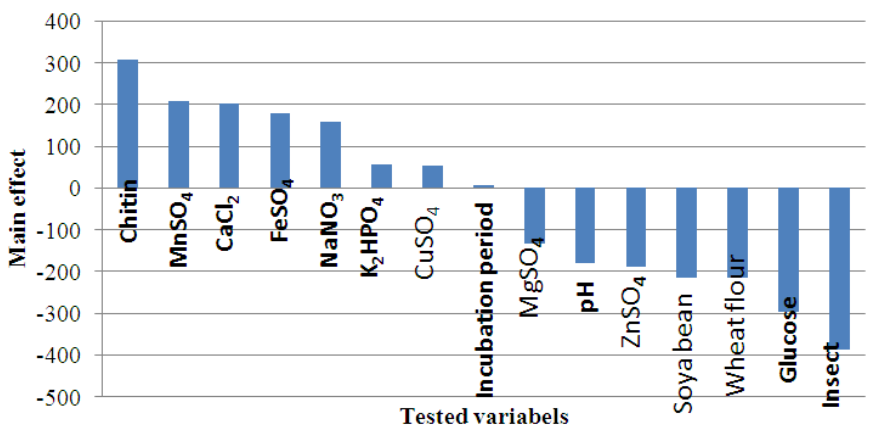

Fig. 1: Effect of culture conditions and medium composition on exochitinase (mU/ml) produced by Aspergillus awamori EM66

Table 2. Statistical analysis of Plackett- Burman design showing coefficient values, effect, $t$-and P-values for each variable on exochitinase analysis Variables

\begin{tabular}{|c|c|c|c|c|c|}
\hline \multirow[b]{2}{*}{$\begin{array}{l}\text { Exochitinase } \\
\text { analysis }\end{array}$} & \\
\hline & 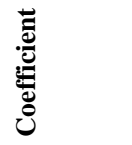 & 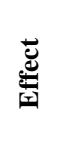 & 雚 & 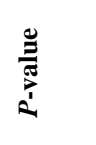 & 递 \\
\hline Intercept & 853.0953 & & & & \\
\hline Incubation period & 4.532 & 6.75 & 0.086573 & 0.4661 & 53 \\
\hline $\mathrm{pH}$ & -38.26265 & -190 & -2.436866 & 0.0139 & 98 \\
\hline Glucose & -987.144 & -297 & -3.809206 & 0.0009 & 99 \\
\hline Insect & -4152.63 & -386 & -4.950686 & 0.0001 & 99 \\
\hline Soya bean & -528.983 & -216 & -2.770332 & 0.0071 & 99 \\
\hline Chitin & 9.469752 & 206 & 2.642076 & 0.0092 & 99 \\
\hline White Flour & -373.737 & -216 & -2.770332 & 0.0071 & 99 \\
\hline $\mathrm{NaNO}_{3}$ & 1768.74 & 158 & 2.026446 & 0.0304 & 96 \\
\hline $\mathrm{CuSO}_{4}$ & 26445.02 & 53 & 0.679757 & 0.2535 & 74 \\
\hline $\mathrm{MgSO}_{4}$ & -529.596 & -134 & -1.718632 & 0.0531 & 94 \\
\hline $\mathrm{K}_{2} \mathrm{HPO}_{4}$ & 2311.588 & 57 & 0.73106 & 0.238 & 76 \\
\hline $\mathrm{ZnSO}_{4}$ & -193353.7 & -180 & -2.30861 & 0.0178 & 98 \\
\hline $\mathrm{FeSO}_{4}$ & 181015.2 & 180 & 2.30861 & 0.0178 & 98 \\
\hline $\mathrm{MnSO}_{4}$ & 10997.6 & 307 & 3.937462 & 0.0007 & 99 \\
\hline $\mathrm{CaCl}_{2}$ & 4499.06 & 203 & 2.603599 & 0.01 & 99 \\
\hline
\end{tabular}

Chitin also was an important factor for chitinase production by Streptomyces sp. Da11 (Han et al., 2008). Similar to 
our result, $\mathrm{MnSO}_{4}$ was found to enhance chitinase production by Aspergillus terreus (Ghanem et al., 2010). It was also mentioned as one of the most important factors affecting chitinase production by Bacillus thuringiensis (Sarrafzadeh and Hussein, 2012). On contrary, (Sharaf 2005) reported that $\mathrm{MnSO}_{4}$ was an inhibitor for chitinase production by Alternaria alternate. Our results also showed that $\mathrm{CaCl}_{2}$ activated the production of exochitinase. Similarly, it was found that $\mathrm{CaCl}_{2}$ activated Pantoea dispersa chitinase production (Gohel et al., 2004). Building on previous results, a medium including ( $\mathrm{g} \%$ ), (glucose, 0.2; insect, 0.1; soyabean, 0.2; wheat flour, 0.2; $\mathrm{NaNO}_{3}, 0.02 ; \mathrm{CuSO}_{4}, 0.001$; $\mathrm{MgSO}_{4}, 0.05 ; \mathrm{K}_{2} \mathrm{HPO}_{4}, 0.2 ; \mathrm{FeCl}_{3}, 0.001 ; \mathrm{CaCl}_{2}, 0.05$ at pH; 8). It was used as a plan medium for further investigations and the cultures were incubated for 6 days.

\section{Optimization of the culture conditions by central composite design}

For searching to the proper concentration for the most effected medium components (chitin, $\mathrm{MnSO}_{4}$ and $\mathrm{CaCl}_{2}$ ) showed confidence level with about $98 \%$ supported the highest chitinase productivity in the Plackett-Burman design. CCD experimental was employed coded and un-coded level of the three independent variables was recorded in Table 3. Also, the results in table.3. referred to the CCD experimental plan, the observed and predicted exochitinase production. Multiple regression analysis of the experimental data reported the following second order polynomial Eq. (6):

$$
\begin{aligned}
& \mathrm{Y}_{\text {activity }}=-4462.211+4591.092 \mathrm{X}_{1}+1.160 \mathrm{E} 6 \mathrm{X}_{2}+62355.551 \mathrm{X}_{3} \\
& -604.012 \mathrm{X}_{1}{ }^{2} \quad-\quad 5.749 \mathrm{E} \mathrm{X}_{2}{ }^{2}-87493.312 \mathrm{X}_{3}{ }^{2} \\
& -74853.051 \mathrm{X}_{1} \mathrm{X}_{2}-16412.830 \mathrm{X}_{1} \mathrm{X}_{3}-3.522 \mathrm{E} \mathrm{X}_{2} \mathrm{X}_{3} \quad \text { Eq. } 6
\end{aligned}
$$

Where $\mathrm{Y}$ activity was the response (exochitinase production) and $X_{1}, X_{2}$ and $X_{3}$ were the coded values of the test variables (chitin, $\mathrm{MnSO}_{4}$ and $\mathrm{CaCl}_{2}$ ) respectively. The graphical representations of the regression equation was represented in the three-dimensional response surface and the two-dimensional contour plots graphs. They were fundamentally important for showing the relations between the interaction effects of the estimated factors and the response value. Fig. 2. A-C showed the response surface and contour plots of chitin and $\mathrm{MnSO}_{4}, \mathrm{MnSO}_{4}$ and $\mathrm{CaCl}_{2}$, also chitin and $\mathrm{CaCl}_{2}$ on exochitinase production respectively, the other component was fixed at zero level. Regression analysis results are shown in Table 4. analyzing the results of central composite designed experiments data. It is recognized the increase in $t$-value magnitude, the decrease in $p$ value, resulting more consideration of the corresponding coefficient (Aravindan and Viruthagiri, 2007). This implies that the variable with the largest effect represented in the linear effect of the $\mathrm{CaCl}_{2}$ concentration and the squared term of the $\mathrm{CaCl}_{2}$ concentration. In this finding, it was reported that $\mathrm{CaCl}_{2}$, played a role to predict optimum chitinase production (Gohel et al., 2004). In this finding, it was reported that $\mathrm{CaCl}_{2}$, played a role to predict optimum chitinase production (Gohel et al., 2004). Table 5. showed that F-value obtained by (ANOVA) analysis was (5.622) confirming the model significant. Moreover Prob> F (0.006) was less than 0.05 showed highly significant. $\left(\mathrm{R}^{2}\right)$ was evaluated as 0.914 for exochitinase activity (a value of $R^{2}>0.75$ insuring the model aptness). This result indicated that the statistical model recorded $91.4 \%$ of variability in the response. Model goodness could be tested by the determination of coefficient $\left(\mathrm{R}^{2}\right)$ and correlation coefficient $(R)$. The $R^{2}$ value is always between 0 and 1. The closer the $\mathrm{R}^{2}$ to 1 , referred to model powerful and better predicted response (Munk et al., 1963). $\mathrm{R}$ value (0.8340) concerning (Eq. 6) was near 1. This pointed to a close coincide among the experimental results and the theoretical values determined by equation model.

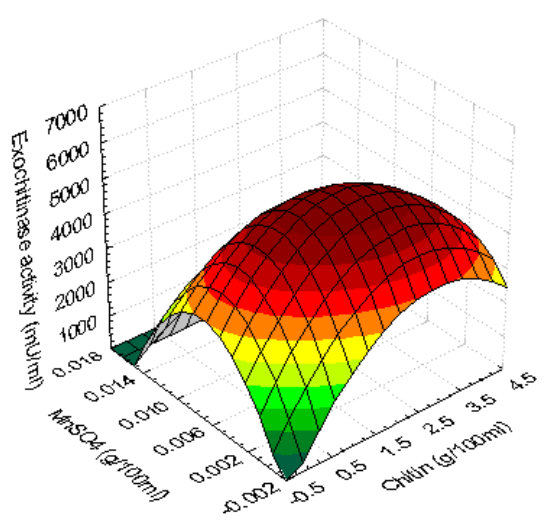

Fig 2. A. Response surface plot of exochitinase production by Aspergillus awamori EM66 showing the interactive effects of different concentrations of chitin and $\mathrm{MnSO}_{4}$ at $\mathrm{X}_{3}=0$

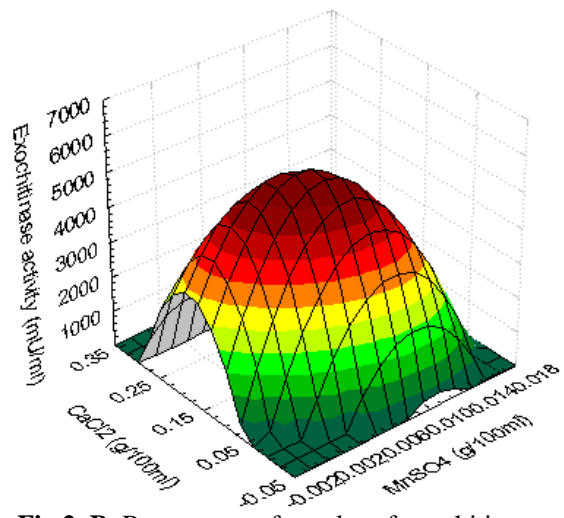

Fig 2. B. Response surface plot of exochitinase production by Aspergillus awamori EM66 showing the interactive effects of different concentrations of $\mathrm{CaCl}_{2}$ and $\mathrm{MnSO}_{4}$ at $\mathrm{X}_{1}=0$

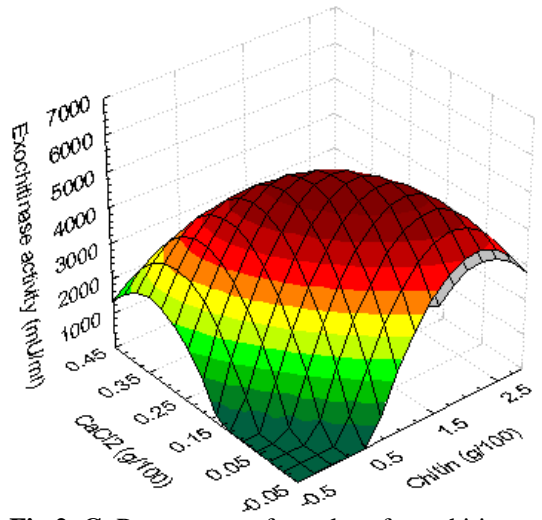

Fig 2. C. Response surface plot of exochitinase production by Aspergillus awamori EM66 showing the interactive effects of different concentrations of chitin and $\mathrm{CaCl}_{2}$ at $\mathrm{X}_{2}=0$ 
Table 3: Central composite design (CCD) consisting of 20 experiments for three experimental factors in coded and actual values for the production of exochitinase by Aspergillus awamori EM66.

\begin{tabular}{|c|c|c|c|c|c|c|c|c|}
\hline \multirow{3}{*}{$\begin{array}{l}\text { Trial } \\
\text { No. }\end{array}$} & \multicolumn{6}{|c|}{ Factors levels } & \multirow{2}{*}{\multicolumn{2}{|c|}{$\begin{array}{c}\begin{array}{c}\text { Exochitinase } \\
(\mathrm{mU} / \mathrm{ml})\end{array} \\
\end{array}$}} \\
\hline & \multicolumn{2}{|c|}{ Chitin $\left(X_{I}\right)$} & \multicolumn{2}{|c|}{$\mathrm{MnSO}_{4}\left(X_{2}\right)$} & \multicolumn{2}{|c|}{$\mathrm{CaCl}_{2}\left(X_{3}\right)$} & & \\
\hline & Coded & Actual (g\%) & coded & Actual (g\%) & Coded & Actual (g\%) & Experimental & Predicted \\
\hline$\overline{1^{\mathrm{a}}}$ & -1 & 0.5 & -1 & 0.0020 & -1 & 0.05 & $1072.00 \pm 79$ & 1834 \\
\hline $2^{\mathrm{a}}$ & +1 & 2.0 & -1 & 0.0020 & -1 & 0.05 & $4445.80 \pm 22$ & 5000 \\
\hline $3^{\mathrm{a}}$ & -1 & 0.5 & +1 & 0.0080 & -1 & 0.05 & $4112.36 \pm 56$ & 4063 \\
\hline $4^{\mathrm{a}}$ & +1 & 2.0 & +1 & 0.0080 & -1 & 0.05 & $5574.40 \pm 16$ & 6555 \\
\hline $5^{\mathrm{a}}$ & -1 & 0.5 & -1 & 0.0020 & +1 & 0.2 & $5227.39 \pm 136$ & 5618 \\
\hline $6^{\mathrm{a}}$ & +1 & 2.0 & -1 & 0.0020 & +1 & 0.2 & $3890.07 \pm 67$ & 4094 \\
\hline $7^{\mathrm{a}}$ & -1 & 0.5 & +1 & 0.0080 & +1 & 0.2 & $3778.93 \pm 14$ & 4678 \\
\hline $8^{\mathrm{a}}$ & +1 & 2.0 & +1 & 0.0080 & +1 & 0.2 & $3445.49 \pm 124$ & 3477 \\
\hline $9^{\mathrm{b}}$ & -2 & 0.25 & 0 & 0.0040 & 0 & 0.1 & $3112.06 \pm 17$ & 3834 \\
\hline $10^{\mathrm{b}}$ & +2 & 4.0 & 0 & 0.0040 & 0 & 0.1 & $4556.94 \pm 51$ & 4147 \\
\hline $11^{\mathrm{b}}$ & 0 & 1.0 & -2 & 0.0010 & 0 & 0.1 & $4401.55 \pm 78$ & 3919 \\
\hline $12^{\mathrm{b}}$ & 0 & 1.0 & +2 & 0.016 & 0 & 0.1 & $514.56 \pm 5$ & 523 \\
\hline $13^{\mathrm{b}}$ & 0 & 1.0 & 0 & 0.0040 & -2 & 0.025 & $3290.10 \pm 73$ & 3687 \\
\hline $14^{\mathrm{b}}$ & 0 & 1.0 & 0 & 0.0040 & +2 & 0.4 & $2058.24 \pm 102$ & 1688 \\
\hline $15^{\mathrm{c}}$ & 0 & 1.0 & 0 & 0.0040 & 0 & 0.1 & $5998.91 \pm 374$ & 5256 \\
\hline $16^{\mathrm{c}}$ & 0 & 1.0 & 0 & 0.0040 & 0 & 0.1 & $5968.90 \pm 124$ & 5256 \\
\hline $17^{\mathrm{c}}$ & 0 & 1.0 & 0 & 0.0040 & 0 & 0.1 & $5986.05 \pm 16$ & 5256 \\
\hline $18^{\mathrm{c}}$ & 0 & 1.0 & 0 & 0.0040 & 0 & 0.1 & $5994.62 \pm 282$ & 5256 \\
\hline $19^{\mathrm{c}}$ & 0 & 1.0 & 0 & 0.0040 & 0 & 0.1 & $5977.47 \pm 181.11$ & 5256 \\
\hline $20^{\mathrm{c}}$ & 0 & 1.0 & 0 & 0.0040 & 0 & 0.1 & $5998.33 \pm 249$ & 5256 \\
\hline
\end{tabular}

${ }^{\mathrm{a}}$ Fractional $2^{3}$ factorial design, ${ }^{\mathrm{b}}$ star points, ${ }^{\mathrm{c}}$ central points.

Table 4: Model coefficients and Analysis of variance (ANOVA) test estimated by multiples linear regression for exochitinase.

\begin{tabular}{ccccc}
\hline Term & Regression coefficient & Standard error & $\boldsymbol{t}$ - test & P-value \\
\hline Intercept & -4462.211 & 1958.690 & -2.278 & 0.046 \\
$X_{1}$ & 4591.092 & 1423.223 & 3.226 & 0.009 \\
$X_{2}$ & $1.160 \mathrm{E} 6$ & 355805.862 & 3.261 & 0.009 \\
$X_{3}$ & 62355.551 & 14232.234 & 4.381 & 0.001 \\
$X_{1}{ }^{2}$ & -604.012 & 214.858 & -2.811 & \\
$X_{2}$ & $-5.749 \mathrm{E} 7$ & $1.343 \mathrm{E} 7$ & -4.281 & 0.018 \\
$X_{3}^{2}$ & -87493.312 & 21485.780 & -4.072 & 0.002 \\
$X_{1} X_{2}$ & -74853.051 & 144157.809 & -.519 & 0.002 \\
$X_{1} X_{3}$ & -16412.830 & 5766.312 & -2.846 & 0.017 \\
$X_{2} X_{3}$ & $-3.522 \mathrm{E} 6$ & $1.442 \mathrm{E} 6$ & -2.443 & 0.035 \\
\hline
\end{tabular}

$\mathrm{F}$ value $=5.622 ; \mathrm{P}$ value $=0.006 ; \mathrm{R}^{2}=0.914 ; \mathrm{R}=.8340$

Table 5: Summary of the mortality percentages of the three lepidopteran pests after treatment with crude exochitinase.

\begin{tabular}{lccc}
\hline \multicolumn{1}{c}{ Pest } & \% Larval Mortality & \% Pupal Mortality & \% Total Mortality \\
\hline Galleria mellonella & 84 & 8 & 92 \\
Spodopteralittoralis & 76 & 10.67 & 86.67 \\
Agrotisipsilon & 58.67 & 6.67 & 65.67 \\
\hline
\end{tabular}

\section{Model Validation}

Validation was carried out under optimized medium conditions. It was predicted by the polynomial model. The experimental exochitinase production of $5886 \mathrm{mU} / \mathrm{ml}$ was recorded. This result was close to its predicted value $(5200 \mathrm{mU} / \mathrm{ml})$ after 6 days of fermentation validating the proposed model. An overall 22.2fold increased in exochitinase production was being achieved after RSM application. This reflected the success and value of optimization process. Many reports were mentioned in optimization of exochitinase productivity by response surface methodology. Exochitinase produced by marine isolate Pantoea dispersa increased about 3.9\% after optimization by RSM (Gohel et al., 2004). Aeromonass chubertii chitinase increased about 1.6 $\%$ more than primary medium (Liu et al., 2013). On the other hand, chitinase produced by Streptomyces sp. Da11 associated with the South China Sea sponge Craniella australiensis increased about 39\% with (RSM) optimization (Han et al., 2008).
The optimization strategy led to an increased in chitinase production in the strains Streptomyces sp. NK1057, NK528 and NK951 by 29, 9.3 and 28\%, respectively (Sarrafzadeh and Hussein, 2012).

Exochitinase productivity by Aspergillusa wamori EM66 under submerged fermentation was effective and worthy optimized by using Plackett-Burman design and central composite design for selecting the statistically important factors and evaluation their optimal concentrations and illustrated graphically by second order polynomial model prepared by central composite design. For determination the relationship between the three factors and the exochitinase yield. Final components concentrations optimized with RSM medium were $\mathrm{g} \%$ : (Glucose, 0.2; insect,0.1; Soyabean,0.2; Chitin, 1.0; Wheat flour,0.2; $\mathrm{NaNO}_{3}, 0.02 ; \mathrm{CuSO}_{4}$, 0.001; $\mathrm{MgSO}_{4}, 0.05 ; \mathrm{K}_{2} \mathrm{HPO}_{4}, 0.2 ; \mathrm{FeCl}_{3}, 0.001 ; \mathrm{MnSO}_{4}, 0.004$; $\mathrm{CaCl}_{2}, 0.1$ ). The initial $\mathrm{pH}$ was limited to 8 and the cultures were incubated for 6 days. 


\section{Enzyme partial purification}

The crude enzyme was fractionated by using absolute ethanol (30-80\%) W/V. The most promising fraction was obtained at $30 \%$ this result suggested that the exochitinase had low molecular weight. Its total activity and protein content recorded $23.34 \mathrm{U}$ and $0.837 \mathrm{mg}$, respectively. This result referred to about 18 times purification fold compared to the preliminary crude culture filtrate. Accordingly, the specific activity was calculated to be $27.89 \mathrm{U} / \mathrm{mg}$. The high specific activity of this enzyme gave it tremendous interest; since it referred that it approaches to purity.

\section{Efficiency of the exochitinase against some lepidopteran pests}

The partial pure enzyme was tested against three serious lepidopteran pests, larvae of the black cutworm, A. ipsilon, larvae of the Egyptian cotton leaf worm, S. littoralis and larvae of the greater wax moth, G. mellonella. The results in table 5.showed that exochitinase had a great effect on the larvae of the three tested pests. The maximum effect of the enzyme was noticed with exochitinase addition to the artificial diet of $G$. mellonella with a mortality percentage of $84 \%$ for the larvae and $8 \%$ for pupae and the total percentage reached to $92 \%$. The treated larvae stopped feeding and suffered from recognizable blacking and severe rot which leads to their death (Fig.3, 4).

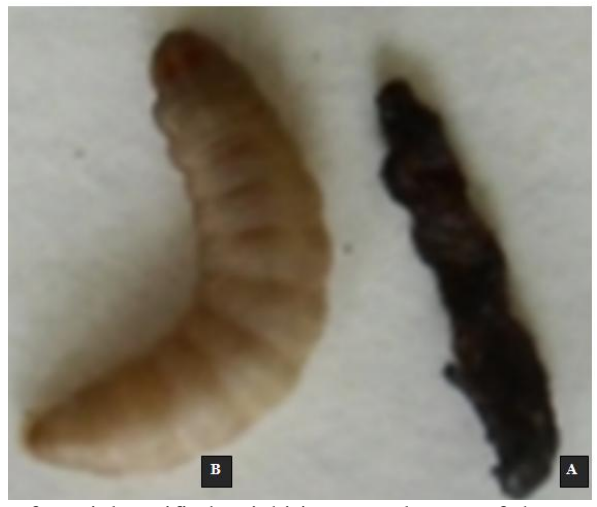

Fig 3: Effect of partial purified exichitinase on larvae of the great wax moth, Galleria mellonella,A. larva after treatment, B. larva without treatment.

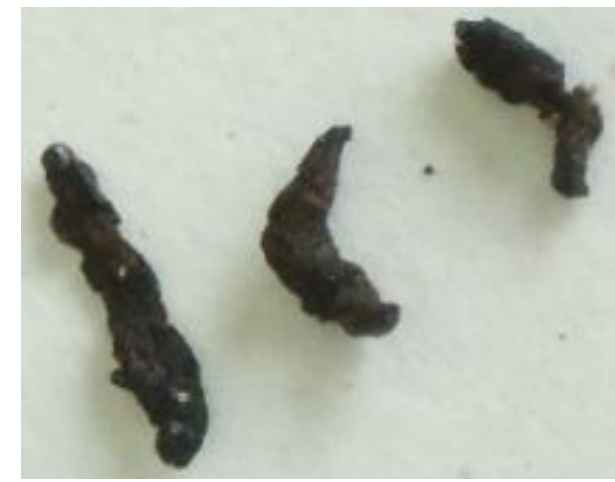

Fig 4: Effect of partial purified exichitinase on different stages of larvae of the great wax moth, Galleria mellonella

When the exochitinase sprayed on castor leaves and fed to the cotton leaf worms, $86.67 \%$ total mortality of S. littoralis was recorded. Meanwhile, less effect of the enzyme (the total mortality reach to $65.67 \%$ ) was noticed with the treatment of larvae of $A$. ipsilon with the enzyme. Great attention to the chitinolytic enzymes has been progress due to their possible involvement as defensive agents against chitin-including pestiferous and pathogenic organisms, like insects, nematodes, and fungi (Munk et al., 1963, Carr and Klessig, 1989, Linthorst, 1991, Sahai and Manocha, 1993). The peritrophic membrane and exoskeleton of insects act as physicochemical barriers to environmental hazards and predators. Both are composite materials made up primarily of chitin and protein, Chitinase of family 18 and 19 have a catalytic reaction and can be described as being similar to lysozyme and chitosanase in its mode of action (Sahai and Manocha, 1993). Another effect of chitinase could be revealed to that the microbial chitinases could be partially digesting the peritrophic membrane. This helping the microbes and their toxins in peritrophic membrane penetration (Smirnoff and Valero, 1983, Sneh et al., 1983, Shahabuddin and Kaslow, 1993, Wiwat et al.1996, Chandrasekaran et al., 2012).

\section{CONCLUSIONS}

This study is aiming to improve the exochitinase productivity for honey isolate Aspergillus awamori EM66. Statistical experimental design was used for optimization process. Estimation the constituents optimal concentrations have clear influencing on enzyme productivity can be obtained by a highly significant quadratic polynomial equation obtained by the central composite design. A high similarity between the predicted and experimental results was noticed. This reflected RSM accuracy and applicability to optimize the exochitinase production process. Mortality (92\%) was recorded when partial pure enzyme was applied to the diet of both larva and pupal of Galleria mellonella wax, followed $86.67 \%$ and $65.67 \%$ mortality when fungal exochitinase was applied for larva of Spodoptera littoralisn and Agrotis ipsilon respectively. Aspergillus awamori EM66 exochitinase could be serving as an effective biopesticide to control harmful pests which destroy importantly economic crops instead of hazardous chemical pesticide.

\section{Financial support and sponsorship: Nil.}

Conflict of Interests: There are no conflicts of interest.

\section{REFERENCES}

Adinarayana K, Ellaiah P, Srinivasulu B, Bhavani R, Adinarayana G. Response surface methodological approach to optimize the nutritional parameters for neomycin production by Streptomyces marinens is under solid-state fermentation. Process Biochem, 2003; 38: $1565-1572$.

Aravindan R, Viruthagiri T. Sequential optimization of culture medium for extracellular lipase production by Bacillus spharicus using statistical methods. J Chemical Technol Biotechnol, 2007; 8: 460 - 470.

Awad GEA, Amer H, El-Gamal EW, Helmy WA. Elnashar MM M. Response Surface Methodological Approach to Optimize The Nutritional Parameters For Invertase Production by lactobacillus brevies 
Mm-6 isolated from breast milk and its immobilization on grafted alginate beads. Carpohydr Polym, 2013; 93: 740- 746.

Balachowsky AS. Entomologie Appliquée à l'Agriculture, Vol.IL épidoptères. Paris: Masson, 1972; 1131-1133.

BoxGEP, Hunter, WG, Hunter JS. Statistics for Experiments. An introduction to design. Data analysis and model analysis. John Wiley and sons : New York 1978; 291-334.

Brzezinska MS , Jankiewicz U. Production of Antifungal Chitinase by Aspergillus niger LOCK 62 and Its Potential Role in the Biological Control. Curr Microbiol, 2012; 65: 666-672.

Carr JP, Klessig D F. Genetic Engineering - Principlesand Methods. 11, ed J. K. Setlow,1989; p. 65. Plenum Press, New York.

Chandrasekaran R, Revathi K, Nisha S, Kirubakaran SA, Narayanan SS, Nathan SS.Physiological effect of chitinase purified from Bacillus subtilis against the tobacco cutworm Spodoptera litura Fab. Pesticide Biochem and Physiol, 2012; 104: 65-71.

Chuan LD. Review of fungal chitinases. Myc, 2006; 161, 345-

366.

Crosby, A.W. Ecological Imperialism: The Biological Expansion of Europe, 900-1900. Cambridge University Press, 2004; 188. ISBN 0-521-54618-4.

Elibol M, Dursun O.Response surface analysis of lipase production by freely suspended Rizopus arrhizus. Process Biochem, 2002; 38: 367-372.

Esawy MA, Ahmed, EF, Helmy WA, Mansour NM, El-Senousy WM, and El-Safty MM. Production of levansucrase from novel honey Bacillus subtilis isolates capable of producing antiviral levans. Carbohydr Polym, 2011; 36: 823-830

Esawy MA, Abdel-Fattah AM, Ali MM, Helmy WA, Tai HAA, Hashem A.M.; Awad E.A. Levansucrase optimization using solid state fermentation and levan biological activities studies. Carbohydrate polymer 2013;96:332-41.

Esawy M A, Mansour S H, Ahmed E F Hassanein NM and El Enshasy HA. Characterization of extracellular dextranase from a novel halophilic Bacillus subtilisNRC-B233b a mutagenic honey Isolate under solid state fermentation E j chem.2012; 9: 1494-1510.

Ghanem KM, Al-Garni SM, Al-Makishah N H. Statistical optimization of cultural conditions for chitinase production from fish scales waste by Aspergillus terreus. African J Biotechnol, 2010;9: 5135514.

Gohel V,Megha C, Vyas P, Chhatpar HS. Strain improvement of chitinolytic enzyme producing isolate Pantoea dispersa for enhancing its biocontrol potential against fungal plant pathogens Ann Microbiol. 2004;54: 503-515.

Gooday GW, The ecology of chitin degradation. Advances in Microbial Eco, 1990; 11: 387-430.

Graham LS, Sticklen MB. Plant chitinases. Can J Bot M, 1994; 72: 1057-1083.

Güz N, Dağeri A, Erdoğan T, Mousavi M, Bayram S, Gürkan MO. Transcriptional profiling of transferrin gene from Egyptian cotton leaf worm, Spodoptera littoralis. 2013. 37: 582-590 Turk J Biol

Han Y, Zhiyong Li, Miao X, Zhang F. Statistical optimization of medium components to improve the chitinase activity of Streptomyces sp. Da11 associated with the South China Sea sponge Craniella australiensis. Process Biochem, 2008; 43: 1088-1093.

Hussein MA. Utilization of entomopathogenic nematodes for the biological control of some lepidopterous pest Entomology (BioControl). Entomology Dept. Faculty of Science, Ain Shams University,2004; Egypt Pp.203.

Kramer KJ, Muthukrishnan S, Lowell J, White F. Chitinases for insect control, in: N. Carozzi, M. Koziel (Eds.), Advances in Insect Control: The Role of Transgenic Plants, Taylor and Francis, Bristol.1997; 185-193.

Kansoh AL, Kheiralla ZH, Ahmed HA, Kahill TAK, Abd ElHameed EK and Esawy* MA. Morphological, Molecular and Biochemical Comparative Studies of Two Novel Fungal Honey.Br Microbiol Res J, 2015; 5: 152-168.

Linthorst H J M.Pathogenesis-related proteins of plants. Crit. Rev Plant Sci, 1991; 10:123-150.
Liu $\mathrm{CL}^{1}$, Lin TH, Juang RS. Optimization of recombinant hexaoligochitin-producing chitinase production with response surface methodology.2013; Int J Biol Macromol 62:518-22.

Lowry, OH, Rosebrough, N. J., Farr, A. L., \& Randall, R. J. Protein measurement with folin phenol reagent. The Journal of Biological Chemistry, 1951;193: 265-275.

Maisuria VB, Gohel V, Mehta AN, Patel RR ; Chhatpar HS. Biological control of $\quad$ Fusarium wilts of pigeonpea by Pantoea dispersa, a field assessment Ann Microbiol, 2008; 58:177-185.

Matsumoto Y, Castañeda GS, Revah S, Shirai K. Production of $\beta-\mathrm{N}$-acetyl hexosaminidase of Verticillum lecanii by solid state fermentation and submerged fermentation utilizing shrimp waste silage as substrate and inducer. Process Biochem. 2004; 39: 655-671.

Metwally HMS, Hafez GA, Hussein MA, Salem HA, Saleh, M M E. Low Cost Artificial Diet for Rearing the Greater Wax Moth, Galleria mellonella L. (Lepidoptera: Pyralidae) as a Host for Entomopathogenic Nematodes. Egypt J Biol Pest Control. 2012; 22: 15-17.

Munk, V, Pásková J, Hanus, J. Glucose oxidase of Aspergillus niger. Folia Microbiol, 1963; 8: 203 -214.

Nawani NN, Kapadnis BP, Das AD, Rao, AS, Mahajan SK. Purification and characterization of a thermophilic and acidophilic chitinase from Microbispora sp. V2. J App1 Microbiol. 2002; 93:965-975.

Nawani NN, Kapadnis BP (2005) Optimization of chitinase production using statistics based experimental designs. Process Biochem, 2005; 40: 651-660.

Plackett RL, Burman JP. The design of optimum multifactorial experiments. Biometrika,1946; 33: 305-25.

Rattanakit N, Yano SH, Plikomol A, Wakayama M, Tachiki T Utilization of shellfish waste as a substrate for solid-state cultivation of Aspergillus sp. J Biosci Bioeng, 2007; 103: 535-541.

Ren X, Yu D, Han S, Feng Y. Optimization of recombinant hyperthermophilic esterase production from agricultural waste using response surface methodology. Bioresour Technol.,197: 2006; 2345-2349.

Robinson GS, Ackery PR, Kitching IJ, Beccaloni, GW \& Hernández LM.HOSTS - A Database of the World's Lepidopteran Hostplants. Natural History Museum, London 2001.

Rui L, Wei-chang C, Wei-peng W, Wen-yan T, Xue-guang Z. Extraction, characterization of Astragalus polysaccharides and its immune modulating activities in rats with gas. Carbohydr Polym, 2009; 17: 738 742 .

Sahai A S, Manocha M S. Chitinases of fungi and plants: their involvement in morphogenesis and host-parasite interaction. FEMS Microbiol Rev, 1993; 11: 317-338.

Shahabuddin M, Kaslow DC. Chitinase: a novel target for blocking parasite transmission? Parasitol. Today, 1993; 9: 252-255.

Sharaf EF. A potent chitinolytic activity of Alternaria alternate isolated from Egyptian black sand. Polish j Microbiol, 2005; 54: 145 151.

Sarrafzadeh, Hussein M. Nutritional Requirements of Bacillus thuringiensis During Different Phases of Growth, Sporulation and Germination Evaluated by Plackett-Burman Method. Iran. J Chem Chem Eng; 2012; 31: 131-136.

Smirnoff WA, Valero JR. Characteristic of a highly concentrated Bacillus thuringiensis formulation against spruce budworm, Choristoneura fumiferana (Lepidoptera: Tortricidae). Can. Entomol, 1983; 115: 443-444.

Singh AK, Mehta G, Chhatpar HS. Optimization of medium constituents for improved chitinase production by Paenibacillus sp. D1 using statistical approach. Lett. Appl. Microbiol. 2009; 49: 708-714.

Sneh B, Schuster S, Broza M. Insecticidal activity of Bacillus thuringiensis strains against the Egyptian cotton leaf worm, Spodoptera littoralis Boisd. (Lep.:Noctuidae). Entomophaga, 1981; 26: 179-190.

Sneh, B.; Schuster, S.; Gross, S. Improvement of the insecticidal activity of Bacillus thuringiensis var. entomocidus on larvae of Spodoptera littoralis (Lepidoptera, Noctuidae) by addition of chitinolytic bacteria, aphagostimulant and a UV-protectant. Z. ang, Entomology. 1983; 96:77-83.

Tanaka T, Fujiwara S, Nishikori S, Fukui T, Takagi Imanaka, T. A Unique Chitinase with Dual Active Sites and Triple Substrate 
Binding Sites from the Hyperthermophilic Archae on Pyrococcus kodakaraensis KOD1. Appl Environ Microbiol. 1999; 65: 5338-5344.

Vionis AP, Niemeyer F, Karagouni AD, Schrempf $H$. Production and processing of a 59-kilodalton exochitinase during growth of Streptomyces lividans carrying p CHIO12 in soil microcosms amended with crab or fungal chitin. Appl Environ Microbiol. 1996; 62, 1774-1780.

Wejse PL, Ingvorsen K, Mortensen KK. Xylanase production by a novel halophilic bacterium increased 20 -fold by response surface methodology. Enzyme Microb Technol. 2003; 32: 721-727.

Wiwat C, Lertcanawanichakul M, Siwayapram P, Pantuwatana S, Bhumiratana A. Expression of chitinase-encoding genes from Aeromonas hydrophila and Pseudomonas maltophila in Bacillus thuringiensis sub sp. israelensis. Gene, 1996; 179: 119-126
Xia G., C. Jin, J. Zhou, S.Yang, S. Zhang , C. Jin. 2001. Novel chitinase having a unique mode of action from Aspergillus fumigatus YJ-407.Eur. J. Biochem. 2001; 268: 4079-85.

\section{How to cite this article:}

Awad GEA, Abdel Wahab WA, Hussein M, El-diwany A, Esawy MA. Sequential optimizations of Aspergillus awamori EM66 exochitinase and its application asbio- pesticide. J App Pharm Sci, 2017; 7 (02): 067-075. 